\title{
Identifying with science: a case study of two 13-year-old 'high achieving working class' British Asian girls
}

Article

Accepted Version

Wong, B. (2012) Identifying with science: a case study of two 13-year-old 'high achieving working class' British Asian girls. International Journal of Science Education, 34 (1). pp. 43-65. ISSN 0950-0693 doi:

https://doi.org/10.1080/09500693.2010.551671 Available at https://centaur.reading.ac.uk/69984/

It is advisable to refer to the publisher's version if you intend to cite from the work. See Guidance on citing.

To link to this article DOI: http://dx.doi.org/10.1080/09500693.2010.551671

Publisher: Taylor \& Francis

All outputs in CentAUR are protected by Intellectual Property Rights law, including copyright law. Copyright and IPR is retained by the creators or other copyright holders. Terms and conditions for use of this material are defined in the End User Agreement.

www.reading.ac.uk/centaur 
Central Archive at the University of Reading

Reading's research outputs online 


\title{
Identifying with science: A case study of two 13-year-old 'high achieving working class' British Asian girls
}

\author{
Billy Wong \\ Department of Education and Professional Studies, King's College London
}

\begin{abstract}
This paper provides an in-depth, 'case study' style analysis of the experiences of two 13 year old British Asian girls from a larger qualitative study investigating minority ethnic students' aspirations in science. Through the lens of identity as performativity (Butler, 1999) and Bourdieu's (1986) notions of habitus and capital, the ways in which two girls engage with the field of science is examined. Samantha is British-Indian and Fay is British-Bangladeshi and they are both 'top set' students in science, but only one aspired to study triple science, while the other desired to be 'famous'. The experiences of the two girls are explicated in this paper, teasing out their experiences and constructions of science. It is argued that cultural discourses of family, peers and teacher expectations can shape students' perceptions of science and education.
\end{abstract}

\section{Introduction}

In recent years, there have been concerns over the declining numbers of students pursuing the study of science in higher education, raising questions over the future supply of scientists as well as the proficiency of scientific knowledge in the wider population (Osborne \& Dillon, 2008). Previous research has found that students tend to have a positive interest in science at the end of primary school (age 10-11) (Murphy \& Beggs, 2005), but such enthusiasm appears to decline dramatically by age 14 (Osborne, 2008; Tai, Qi Liu, Maltese, \& Fan, 2006), suggesting the period from which students enter secondary school to the point where students select their GCSE ${ }^{i}$ subjects (i.e. Key Stage 3, age 11-14) to be pivotal in consolidating students' views about science.

This paper draws on an ongoing doctoral study ${ }^{\mathrm{ii}}$ which looks into minority ethnic students' aspirations and views of science, in response to concerns over the lack of minority ethnic groups (in the UK and US) in the field of science (Elias, Jones, \& McWhinnie, 2006; Lewis, Menzies, Nájera, \& Page, 2009). Previous studies found educational (under)achievement to be accountable for their 'leaky' engagements with science at compulsory and post-compulsory education (Elias et al., 2006; National Academies Press, 2010). According to Roberts (2002), the continuing decline in the study of school science represents a major economic concern over the future health and wealth of the UK (and US, National Academies Press, 2010) economy, because science and technology constitutes the foundation and progression of contemporary 'knowledge-based' societies.

The study is sociologically informed and focuses on the intersecting factors of 'race'/ethnicity, social class and gender as forces of influence in shaping students' views of science, especially with respect to dominant images of scientists, and science in general, as typically seen as a field of, and for, the archetypal 'white middle class male' (Aikenhead, 1996; 
Burnell, 2009). Embodied within these interweaving social factors is the notion of identity, particularly the ways in which science is seen by minority ethnic groups as a field for 'people like me' (or 'not for me', Jenkins \& Nelson, 2005), whose ethnic, class and/or gender identities may appear inconsistent with the popularly perceived characteristics of science. For instance, studies concerning gender and science in school tend to conclude that boys are more positive in their views of science than are girls (Murphy \& Whitelegg, 2006), and that girls receive fewer encouragements from science teachers (Brickhouse, Lowery, \& Schultz, 200o), since science is argued to reflect (white) 'masculine' values (Baker, 1998; Blickenstaff, 2005; Whitehead, 1996). In other words, girls may be reluctant to participate (or engage) in science because they often perceive the identities of scientists as inconsistent with their own (Brotman \& Moore, 2008; Ceci \& Williams, 2007). Likewise, the influence of gender can also be crosscut by other social factors, notably that of class (Adamuti-Trache \& Andres, 2008) and ethnicity (Elias et al., 2006), where 'working class' and minority ethnic groups may disassociate from science earlier than their 'middle class' and White counterparts. Indeed, the American Association for the Advancement of Science (AAAS, 1998) emphasised that science and science-related careers were traditionally viewed as privileges for the elite (i.e. 'white middle class male') and thus, certain groups of people, such as women and minority ethnic groups, are less likely to gain access to valuable scientific knowledge (AAAS, 1998), resulting in their underrepresentation in science-related careers (in the US). As noted by Ong (2005: 596), '[the] widespread images of ordinary scientists as white men effectively discourage many talented young women and underrepresented minorities from exploring physics [and science] as an option'. In other words, if certain subjects (or careers) are generally perceived (by the dominant view) to be occupied by people of certain traits (e.g. gender, physique, social class, ethnicity), then students who do not wish to be associated, or does not have those advertised characteristics, may opt for other subjects (or careers) that are more consistent with their self-identity.

In this paper, the notion of identity is understood as an ongoing project of constructions and performances, constituting a continuous process of negotiation within complex structural and agentic relationships (Butler, 1999). In other words, identity is seen as fluid and as always 'in process' (Hall, 1990), conditioned under multiple and unsteady social and structural forces. Within the project of identity constructions and performances, the conceptual tools of Bourdieu $(1977,1986)$ will also be employed as an exploratory lens to test out their applicability in the context of science and identity, in particular his notions of habitus and capital when exploring the resources available to particular ethnic groups, and how the possession of particular capitals may privilege certain groups in various identifications and performances (e.g. in science). As the work of Bourdieu has not been extensively applied in the field of science education (exceptions include Adamuti-Trache \& Andres, 20o8; Brandt et al., 2010; Elmesky \& Tobin, 2005), this paper's adoption of a Bourdieuian analytic lens might offer an alternative viewpoint towards minority ethnic students' education, aspirations and identifications in science.

Bourdieu (1977, p. 86) conceptualised habitus as '[a] system of internalised structures, schemes of perception, conception and action common to all members of the same group or class and constituting the precondition for all objectification and apperception'. In other words, habitus can be understood as the ways in which individuals internalise a particular 
understanding of the social world through (specific) experiences which effectively formulates (and governs) one's way (and boundary) of thinking, acting and approaching the social world. As summarised by Harker (1984, p. 118), 'habitus is the way a culture is embodied in the individual'. Capitals work alongside the habitus, constituting the resources available to individuals which can be seen as generating social dis/advantages. Bourdieu (1986) identified three main types of capitals enabling social reproduction: economic, social and cultural. Economic capital is self-explanatory, representing financial resources. Social capital refers to the resources one is able to draw upon from one's networks of connections. Cultural capital constitutes the 'valued' knowledge within a society or field (e.g. education), typically determined by the dominant groups (e.g. white 'middle class' in the UK) who effectively control and prescribe valuable knowledge, possessions and recognitions. Thus, this study is theoretically informed by the performative nature of identity, focusing on the ways in which one's habitus and available capitals influence and shape students formulation and identification with science.

As will be explained in the next section, this paper explores the experiences of two 13year-old British Asian (one British-Indian and one British-Bangladeshi) 'high achieving working class' schoolgirls: Samantha and Fay. This paper seeks to explore the constructions, perceptions and identifications with (school) science among these two British Asian schoolgirls, with particular reference to their career aspirations. Through the conceptual tools of Bourdieu, the paper explores the complexity of how two similarly positioned individuals can start to diverse in their career aspirations and identifications with science. The findings can shed light into studies which suggests that the underrepresentation of girls and minority ethnic groups in science (at post-compulsory level) to be the result of lower science attainments (Elias et al., 2006; Gilleece, Cosgrove, \& Sofroniou, 2010; Thomson, 2008), since both girls in this paper are considered 'high' achievers. In this paper, the case of Samantha explicates how 'working class' British Asian schoolgirls can aspire to study 'triple science' without interest, while the case of Fay examines how her desires to be 'famous' can potentially interfere with her science education and, in particular, her academic attainment.

\section{Minority Ethnic Pupils and Science}

In the UK, a report prepared for the Royal Society of Chemistry and the Institute of Physics stated that 'the progress of specific ethnic groups through academic chemistry and physics is modelled using the metaphor of a "leaky educational pipeline" (Elias et al., 2006, p. iii). Along this 'pipeline', individuals of specific ethnic groups can be seen to drop out at various stages (either to pursue an alternative career choice or studies or failed to achieve the necessary qualifications to continue in science). For example, in comparison to ethnically Chinese $(69.5 \%)$ and Indian (64.9\%) pupils, data from the Department for Children, Schools and Families (DCSF, 2009) indicate that Afro-Caribbean (35.9\%), Pakistani (39.7\%) and Bangladeshi (44.5\%) pupils in England and Wales generally perform 'less well' in the benchmark achievement of five GCSEs within the range of grades $\mathrm{A}^{*}-\mathrm{C}$ (including and English and Mathematics). The national average was 47.6\% (DCSF, 2009).

While achievement in specific GCSE subjects (i.e. science) was not presented in relation 
to ethnic background, Elias et al. (2006, p. 8) were content that the 'lack of attainment at GCSE level alone potentially goes a long way to explaining the lack of ... [Afro-]Caribbean [and Pakistani and Bangladeshi] scientists at university'. Indeed, Jones \& Elias (2005) found Chinese and Indian students to be proportionally overrepresented ('double', 100\%) in science, engineering and technology (SET) degrees, with UK domicile Chinese and Indian students constituting $0.73 \%$ and $2.46 \%$ of the British higher education student population (in 2001-2), but represented $1.50 \%$ and $5.48 \%$ of students studying SET degrees. Likewise, students from Afro-Caribbean, Pakistani and Bangladeshi ethnic backgrounds are statistically underrepresented in SET degrees (Jones \& Elias, 2005). Thus, Chinese and Indian pupils, on average, are more likely to achieve the benchmark standard at GCSE than those of AfroCaribbean, Pakistani and Bangladeshi ethnic backgrounds. Similar findings were also reported in the US (National Academies Press, 2010) concerning the underrepresentation of minority ethnic students in post-compulsory science education (with the exception of 'Asian' American, such as those with Chinese, Korean and/or Japanese heritages). As can be seen, Chinese and Indian students would typically be examples of 'successful' pupils in this context, demonstrated by high achievements in GCSE and proportionally higher uptakes of science (in higher education). By comparison, 'less successful' groups such as Afro-Caribbean, Bangladeshi and Pakistani pupils tend to perform 'less well' on average at GCSE, and disengage from academic science at its earliest opportunity.

The overall study sample included 46 minority ethnic students (aged 11-14) from seven schools in London ${ }^{\mathrm{iii}}$, who were interviewed (semi-structured) on issues surrounding their views of and aspirations in science, as well as their identifications with the image of science and their views on whether it is a field for the 'white middle class male'. The schools were located in 'urban' and 'suburban' areas of London, in an attempt to garner a spread of minority ethnic participants from different socioeconomic backgrounds ${ }^{\text {iv }}$. However, some schools were approached to target specific minority ethnic groups, meaning the ethnicity of participants were not equally recruited in each of the schools participated. The students were from Indian (four boys, six girls), Chinese (seven boys, six girls), Afro-Caribbean (five boys, four girls), Pakistani (two boys, three girls) and Bangladeshi (eight boys, one girl) ethnic backgrounds, representing examples of 'successful' and 'less successful' achievers in relation to national GCSE and A-level statistics of achievements (DCFS, 2009), and post-compulsory science education or participation (Elias et al., 2006). Minority ethnic students were identified by the gatekeepers as matching the age (11-14) and ethnic criterion of 'Afro-Caribbean', 'Indian', 'Chinese', 'Bangladeshi' or 'Pakistani' heritage ${ }^{\mathrm{v}}$. It is acknowledged that there may be gatekeepers' bias in the inclusion (or exclusion) of particular students, and thus the author explicitly state to gatekeepers that students of any characteristics (e.g. irrespective of 'ability', 'behaviour', 'personality' or 'background') within the age and ethnic criterions could offer invaluable insights to the study. Indeed, a range of students were recruited within and across the five minority ethnic groups.

Students were invited to participate through a letter addressed to their parents, which needs to be signed and returned before students could participate. Students themselves were also required to sign a consent form before their interviews, after the author verbally brief to students of the purpose of the study and that participation is voluntary, as well as their 
confidentiality, anonymity and that they could stop the interview or refuse to answer any questions at anytime (and withdraw without reason). Most students who participated appeared expressive and talkative, with only a handful that tend to response with very short answers, where the author would attempt to rephrase the same question before moving on. Students were offered the chance to choose their own pseudonyms. The interviews were conducted on a one-to-one basis, usually in a quiet empty room within the school ${ }^{\mathrm{vi}}$. The student interviews began with general questions concerning their likes and dislikes in and out of school, before enquiring into their (and what they think of their parents) views towards education and career aspirations. Students' constructions, perceptions and views of science were then probed, with particular references to the gendered, classed and ethnicised imagery of science/scientist. To reduce misunderstandings, the author revisited the key points towards the end of each interview and asks the students to summarise their career aspirations and views of science. All interviews were audio recorded (with permission from students and their parents) and later transcribed verbatim, with student names anonymised.

It is important to note that data garnered in this study represents a form of knowledge co-construction, since the researcher cannot gather data from the 'field' without interruption, or in its 'natural' form (Guillemin and Gullam, 2004). Thus, it is necessary to recognise the role of the researcher in the construction (and production) of research data, since the biographies of the researcher can shape and influence the ways in which participants interact with the research(er) (Rapley, 2001). The researcher in this study is male, in his mid-twenties and of Chinese ethnic background. While the age of the researcher is almost twice of the student participants, the researcher is still 'young' in comparison to the vast majority of (science) teachers in their respective schools, which might encourage students to be 'more relaxed' or 'more open'. While some students may share gender and/or ethnic characteristics as the researcher, this paper is informed by the positions of Rhodes (1994) and Rapley (2001), which refuted the assumption that ethnic (or gender) matching of the researcher and the researched would provide 'more accurate or genuine' accounts, but that 'data gained in the specific interview begin to emerge as just one possible version, a version that is contingent on the specific local interactional context' (Rapley, 2001, p.318). As such, two researchers can validly produce two different accounts from the same source (e.g. participant), which is uniquely shaped, influenced and constructed by a combination of (accountable and unaccountable) factors in the moments of data co-construction.

In this paper the experiences of two 13-year-old British Asian girls are explored in order to tease out the interactions of identity, gender and 'race'/ethnicity. Samantha is from an Indian background and has been selected as an example of a 'successful' ethnic group, in terms of GCSE and A-level achievements in relation to national statistics, while Fay is from a Bangladeshi background, and has been selected as an example of a 'less successful' ethnic group in relation to national statistics for GCSE and A-level attainments.

Samantha was chosen for case study analysis because she was atypical of other Indian girls in the overall study, who tend to command high interest in science as well as sciencerelated career aspirations. Samantha has declining interest in science and aspirations to be a lawyer or doctor. Fay constitutes an 'interesting case' whereby her 'working class' status and her heavy investments in hetero-femininity appears to be resisting the 'working class' trajectories of 
school disengagement common amongst white 'working class' girls in England (e.g. Archer, Halsall, \& Hollingworth, 2007). As such, the use of the 'case studies' of the two girls is intended to enable as in-depth exploration of the complex performativity of identities in relation to the notion of habitus, available capitals and the field of science.

Samantha attends Cranberry School, located in an urban area with a high British-Indian presence, which is reflected in the student composition at Cranberry, as an ethnically diverse school that is dominated by British-Indian students. Fay attends Barton School, located in the suburbs of the same city. However, the school is considered 'urban' by the assistant head teacher as the majority of students in the school commute from an 'urban' area outside the school's residential borough. Students in Barton are also ethnically diverse. According to Ofsted $^{\text {vii }}$ reports, the proportions of students eligible for free school meals in both schools are above the national average, and within their respective local authority, both schools are (slightly) 'below average' in terms of GCSE attainments. Using the benchmarks from DCFS (2002) concerning the expected grades for Year 9 students, both Samantha and Fay may be considered 'high' achievers, which was also recognised by their respective schools, since both girls are placed in the 'top set' for science. However, neither of the two girls viewed science (as a subject) with especially high interest or enthusiasm. Despite this factor, Samantha is determined to study science at the highest level for GCSE (e.g. triple award science ${ }^{\text {viii }}$ ). Fay, on the other hand, seems to disengage from science even when she appears to command various science-related capitals at her disposal. Thus, the aim of the paper is to explicate the ways in which minority ethnic schoolgirls utilise various, and apparently conflicting, discourses in their perceptions and constructions of science.

The two students were individually interviewed for 45-6o minutes and were also observed in their science classroom lessons ( $2 \mathrm{x}$ one hour lessons for Samantha, $4 \mathrm{x}$ one hour lessons for Fay). Observations focused on the ways in which the girls interacted, communicated and participated in science lessons, such as with their peers and with the science teacher. The author adopted an observatory role by being 'out of sight' (e.g. sitting at the back of classroom) to reduce the influences of the researcher on the 'natural' occurrences in the classrooms (DeWalt \& DeWalt, 2001). The technique of 'semi-structure observation' was applied, which means the researcher 'will have an agenda of issues but will gather data to illuminate these issues far less pre-determined or systematic manner' (Cohen, Manion, \& Morrison, 200o, p. 305). Since the purpose of observation was to comprehend science classroom interactions of participating students, the author entered the classroom with a focus on the interactions of particular students (e.g. Samantha and Fay). Fieldnotes made during classroom observations were later written up (usually in the same day) to recount and document the occurrences observed. Samantha and her close group of Indian friends also participated in a discussion group $^{\text {ix }}$ (which lasted 70 minutes) with the focus on parental expectations and general perceptions of science. Their science teachers (Mr Denzin for Samantha, Mr Tallman for Fay) were interviewed for 45 minutes, giving insights into teacher expectations and evaluations of particular pupils. Thus, three data sources were drawn for case study analysis (individual interview with student, science classroom observation of student, teacher interview data and a forth source for Samantha in group discussion data).

Following a social constructionist perspective which emphasises identity as socially 
constructed and discursively produced, the data collected were analysed through a Foucauldian analysis of discourse (Burman \& Parker, 1993; Foucault, 1980), focusing in particular on students' aspirations to study science for GCSE and the future. The social constructionist paradigm can be said to align with the epistemology of interpretivism, which emphasises subjectivity and opposes the assertion of value-free knowledge (e.g. positivism). Enquires into the social world is (subjectively) interpreted by researchers of various preconceptions (Snape and Spencer, 2003). An interpretive approach, therefore, is open to different understandings of realities which stem from various backgrounds and perspectives.

For Foucault (1980), discourse constitutes the particular ways of thinking about the (social) world that comes to be seen as 'natural'. In other words, discourse functions like a set of rules, which vary over time and space, and conditions the ways in which people think and act. A Foucauldian understanding of discourse is concerned with the interplay of power in the creation of social norms and practices that can shape and influence (or even constrain) one's identity and (possible) ways of thinking and doing within particular discourses (Burr, 2003).

Discourse can governs what it means to be, for example, a student, a parent or a scientist, through particular social constructions that are projected and accepted as 'natural' (or the way things are). Discourse is not singular as the same reference (e.g. a scientist) can have more than one implication. For example, the discourse of a scientist may be positively characterised (and perceived) as people who are intelligent, clever or life-changing, but it can also negatively interpreted as people who are 'playing god', dangerous/mad and obsessive. Perceptions of science and scientists, therefore, can be governed by the discourses one is able to draw upon. For instance, an egalitarian discourse - the belief that anyone can be anything - was produced within Fay's talk about people who works as scientists. In that case, Fay's perception about scientists is shaped through a discourse (i.e. understanding of the world) which projects equal opportunity and the freedom of aspirations. Students' ability to utilise discourse, however, can also be conditioned by various social identities and inequalities, such as gender, class or ethnicity. Indeed, Fay also drew on popular gendered discourses of science as a field for men by implying men is clever(er) and thus more able to succeed as scientists (than women). As such, there may be different (and competing) discourses (and understandings) embedded within the same issue (e.g. perception of scientists), and the discourses student are able to produce through their talks can appear multiple and indeed contradictory. In fact, such apparent contradictions (e.g. discourse of science as for anyone and for men) also illustrate the complexity within young people's constructions and interpretations of science and scientists. Thus, the power of discourses can be significant in forming students' aspirations and views of science. As such, analyses are focused on identifying and exploring the discourses drawn on by the two girls in their constructions of science and aspirations, with a focus on the resources (capitals) available to them.

In this paper, interview transcripts were first coded by emerging concepts and themes, with the author 'moving back and forth' between the data and analyses in an iterative process through which the dimensions of concepts (and themes) are refined and/or expanded through the comparison of data (Miles and Huberman, 1994). These concepts and themes were then analysed discursively through the conceptual tools of Bourdieu (e.g. notions of habitus and capitals) to unravel the ways in which Samantha and Fay construct and identify with science. 
In this study, the interpretation of data were primarily guided by Bourdieu's theoretical concepts, such as the notions of habitus and (economic, social and cultural) capitals, as the author examines the data and discourses produced within students' talk about science and aspirations. While this paper draws upon various sources of data (student and teacher interviews, science classroom observations and focus group discussion with Samantha), the findings presented in this study can only be a 'snapshot' of the ways Samantha and Fay identify with science, since the notions of identity, aspiration and views/experiences of science are characterised as fluid, unstable and always 'in process'. The methodology of this study may also be seen to privilege the researcher in the sense that the analyses and interpretations of data are intricately linked with Bourdieu's notions of habitus and capitals, and the concept of identity as performative.

However, the purpose of this study is to raise and explore, from a sociological perspective and through the application of Bourdieuian concepts, some of the potential complexities and challenges for British Asian girls in their identifications with science. In the following sections, the constructions and perceptions of science are teased out through the cases of Samantha and Fay, by analysing the influences of the family, peers and teachers in relation to the notions of identity, habitus and capitals. It is argued that through available social and cultural resources, ('long term') engagement in science can be without interest (Samantha) and ('short-term') achievement in science can be without engagement (Fay).

\section{The Case of Samantha: ('Long-term') Engagement without Interest}

Samantha is a Year 9 (age 13) British-Indian girl of working class background and is considered a high achieving pupil by her 'top set' status in science (and most other subjects). Consistent with existing literatures on the declining interest in science amongst pupils generally in western industrialised countries such as the UK (e.g. Murphy \& Beggs, 2005), Samantha held high interest in science during primary school, but this gradually declined in the early stages of secondary education. As Samantha recalled, 'I used to really like science, like in primary school ... I don't know I'm not really interested in it anymore ... I find it really boring and I just don't really want to listen'. As reflected in her grades, her achievements in science have also stalled at level six since Year 7, with little improvements since. Interestingly, for her GCSE subject choices, Samantha aspired to study 'triple science' - the most comprehensive form of science available at GCSE level - as she (and a small cluster of her friends who were also interviewed) regarded it as 'better', 'smarter' and 'cooler' (Osborne, Simon, \& Collins, 2003). For example, one of her close friends, Becky, reasoned that 'I'm doing triple science, cos I want to be smart'. Indeed, Samantha constructed those who are interested in or who study science, as 'people who are smart enough to be scientists', implying cleverness as a prerequisite for the study of science. It is important to highlight that while Samantha confesses her loss of interest and engagement with science, she opts to continue with science at the highest possible level. As will be discussed, the performativity of identity (Butler, 1999) and Bourdieu's (1986) notions of habitus, social capital and cultural capital can help to decode Samantha's apparent inconsistency between interest and choice of study, given her strong emphasis to study triple science despite declining interest in the subject. 
It is argued that, for Samantha, the route to study triple science appears to be normalised by those around her, notably her family, peers and teachers. In other words, she expects and is expected to study (and aspire to) particular subjects (and professions), such as triple science (and top professions such as doctor or lawyer). Samantha's high aspirations constitute a part of her habitus, which is reinforced by her available cultural and social capitals. In the family, Samantha derives social capital (in relation to the study of triple science) from her older brother who is on the verge of completing the course, ensuring that such an avenue is seen as possible and achievable (i.e. safe routes ${ }^{\mathrm{x}}$ ):

I'm aiming for triple science, but I'm not sure if I'm gonna get it because I'm kinda lacking right now, but, erm, when I was upstairs in my brother's room, I was, erm, looking through his drawers and I found a paper, cos that was his revision drawers, and I found a paper which was exactly the same one I did for the science one and he got like the same grade as me ... but he's really clever though, so I wasn't that disappointed cos he's doing the triple science now, so, yeah (Individual interview with Samantha).

Thus, Samantha appears to seek confidence and reassurance by comparing her current grades with her brother's Year 9 scores, as a marker for success and progress. Given that her current achievement is similar to her brother in Year 9, Samantha is able to find a successful precedent in her brother that she can also do well in triple science, especially since she held high regards for him. In this case, older siblings can act as advisors for younger siblings, for they can offer first-hand experience and knowledge of what is required to succeed (Morrow, 1999). For example, Becky's (a close friend of Samantha) older brother cautioned her about the need to be mathematically competent when studying physics.

Samantha also explicated the prestige of triple science for future educational and careers options ('...it can help me in the future and stuff, like good to do that. It's a good qualification'), which shed light on her cultural capital concerning the hierarchy of subject status (Francis, 200ob). Similar findings were also reported by Brickhouse and Potter (2001) in the context of African-American urban schoolgirls, where 'Ruby', one of two girls in the study, admit to have little interests in computers, but yet appear to value her study of computing because of extrinsic reasons, such as 'the promise of a high salary when she entered the workforce' (p. 977) and for college application. Samantha's point is exemplified through her dismissal of art as a GCSE subject, claiming it to be 'a waste of GCSE'. Another friend, Vincy, also rejected art despite her interest in it because she does not consider art as a career ('I know art is something that I enjoy, but like that's not really important, that's not called a job'). As can be seen, the study of triple science appears to offer Samantha (and her peers) a type of desirable identity because it represents cleverness and academic status. Science, in this case, is positively constructed and the identity associated with studying triple science is actively pursued by Samantha (and her peers).

Samantha's interest in being 'clever' and her study of high status subjects (e.g. triple science) links with her careers aspirations, which are to become a doctor or a lawyer. Such 'high' aspirations appear normal within her habitus and available social and cultural capitals. For instance, Samantha states her parents and members of her extended family viewed careers in 
the field of medicine and law as desirable professions, because it is seen as financially secure. In her qualitative study of 10 Indian Americans high school students (whose parents migrated from India), Asher (2002) found economically rewarding careers, such as in medicine or business, to be highly desired within the Indian American family. However, all 10 Indian American students in Asher's (2002) study were from 'upper-middle class' families, but Samantha is 'working class' and she appears to share their high status career aspirations. While studies in the UK have suggested white 'working class' families to have low aspirations and thus low achievements (e.g. Demie \& Lewis, 2010), recent studies also found professional career (and high educational) aspirations to be prominent amongst some minority ethnic groups, irrespective of their social class backgrounds, which suggests classed aspirations can be complicated by ethnicity (e.g. British Chinese in Archer \& Francis, 2007; Chinese American in Zhou, 2005).

While Samantha stressed her choices for the future as free from parental pressure ('[mum] said I can be whatever I want'), Samantha acknowledges that education at university level, and careers in either medicine or law, are highly sought-after ('[mum] really wants a doctor or lawyer in the family'). The fact that Samantha's uncle and aunty are both lawyers meant Samantha has social capital in the field of law, which could be first-hand knowledge about the profession or personal advices on what is achievable ('If I did want to be a lawyer my uncle and aunty can help me a lot because they are either lawyers or solicitors I'm not sure, and so, they can help me a lot and guide me'). In other words, just as Samantha has social capital ('additional' knowledge) about triple science (through her older brother), the prospect of becoming a lawyer is also a route seen to be possible and comparatively 'safe' (through her uncle and aunty), especially since her uncle attended her current secondary school. Samantha's social and cultural capital in facilitating 'high' educational and careers aspirations, and knowledge of what it will take to achieve these, in fact, extends beyond the family. While Samantha's close group of friends' aspired to different (but all professional) occupations, Samantha realised they are in fact all in the 'top sets', which can be mutually beneficial for members within the peer group (Ryan, 2001).

It is interesting to note that Samantha recognises that her peers at school also associate her (Samantha) with medical and scientific interests. As Samantha recalled, 'they probably think I want to be a scientist or a doctor or something involved in that area, I don't know why ... just expect me to be interested in that stuff'. These expectations may stem from Samantha (and her close group of friends) being regarded by large sections of their year group as 'geeks' and 'nerds'. The notion of 'nerds', for Samantha, appears to be understood in relation to high achievement and a hard working ethic ('we're kinda classified as nerds ... because we always do well in exams and stuff, and we try hard'). In this case, it is suggested that the positioning of Samantha and her friends as 'nerds' may actually play in Samantha's favour with regards to her identification with science. This is because her interpretation of 'nerd' identity seems to align with her desired performances of 'cleverness' and being 'high achieving'. In negotiating the term 'nerd', Samantha empathises with being clever ('not really geeky ... just clever') while repositioning their antagonists - who are also regarded as the 'popular' girls - as 'rude' people. As such, Samantha (and her peers) developed the strategy of 'laugh it off' by 'thanking' their antagonists for their 'compliments' (Nayak \& Kehily, 2006). In return, Samantha and her peers 
also negatively constructed (and pathologised) their antagonists as 'immature' ('it makes me wonder ... how are they going to get it ... they don't concentrate in class') and overly 'heterofeminine' ('they play games that are really childish ... [like] truth or dare ... and dirty ... the girls always talk about boys'). For Samantha then, a 'clever' and 'high achieving' identity (which 'rude' people would call 'nerds') appears to be defined against the characteristics of their antagonists (i.e. the 'popular' girls), who are constructed as imprudent and excessively effeminate. Interestingly, and in contrast to the findings of other studies which mainly looked into White students (e.g. Francis, Skelton, \& Read, 2010), Samantha (and her peers) appear to have made few attempts to 'balance out' their performances of 'cleverness' (and 'high achieving') pupil identities with performances of hetero-femininity. In fact, the case of Samantha and her peers resembles 'the survivors' in Shain's (2003) study, where British Asian students conform to the (Asian) 'good pupil' stereotype of obedience, hard work and high achievement, and Renold's (2001) 'square-girls', where high-achieving primary schoolgirls reject popular culture and hetero-feminine performances. For instance, classroom (and interview) observations of Samantha and her peers noted them as 'quiet students with 'simple' appearances, who wore little if any make-up, nor had any decorative accessories or jewelleries other than plain coloured headband or hair clips'. Thus, performances of 'cleverness' and hetero-femininity may be constructed by Samantha as two incompatible domains, or what Renold \& Allan (2006) termed the 'feminine-ization of success'.

For Samantha, science (or triple science to be precise) is constructed as a form of identity which confirms (or reaffirms) the status of being 'clever' and 'high achieving'. In fact, Samantha's science teacher was certain she (and her group of close friends) will succeed in triple science, praising her hard working attitudes and good behaviours in class. Research has shown that the dominant discourse positions British Asian (Indian, Pakistani, Bangladeshi) schoolgirls as being quiet, passive and obedient, and such views may have played into Samantha's teacher's expectations of British Asian girls as resembling the 'good pupil' (Shain, 2003). Similarly, literatures in the US also found the 'good girl' identity to be highly valued by science teachers, even if the students lacked particular interests in science (Brickhouse et al., 2000). Indeed, such an identity also appears to be adopted by Samantha and her peers, who regarded themselves as the 'better students' (and 'good pupils'). For instance, Samantha is highly disciplined towards her homework ('[Mum] knows I do my homework') and aspired to complete it with the highest of standards. In fact, Samantha expressed disappointment when her science teacher only noted 'good effort' and 'good attitude' in her work; because she was expecting 'excellent' and 'very good' assessments she reported receiving regularly in her other subjects.

As can be seen, Samantha's social network of fellow 'high achievers' (e.g. her sibling, her extended family and close female friends) are likely to be significant in her construction (and maintenance) of a 'clever' (and 'high achieving') identity as something that is expected and normative for 'people like her'. In other words, it was a part of her habitus - internalised ways of understanding and approaching the social world (Bourdieu, 1986). For instance, Samantha stated her careers aspirations as being in the fields of medicine or law, but she later conceded that 'I don't really know what I want to be, so I just come up with that vision that would like please everyone'. Such a statement highlights the role played by expectations of what 'people 
like me' should be aspiring to. The constituency of 'everyone' can include members of her family, extended family and close friends, as well as her teachers and acquaintances (including those who call her 'nerds') - as their expectations of Samantha all seem to revolve around the performance of 'cleverness'. Likewise, Samantha's desire to study triple science despite her losing interest can illustrate the 'functioning' of her habitus, in what 'people like me' should be studying. In other words, Samantha's habitus and available (cultural and social) capitals seem to have perpetuated the discourse of 'high achievement' and 'high aspiration' which Samantha is obliged to maintain, through performances which reaffirm 'cleverness' and 'high achievement'. As the study of science is understood by Samantha (and her peers) as something 'clever' and what 'high achieving' people do ('some people are smart enough to be scientists'), Samantha's pursuit of triple science reinforces her intent to occupy the identity of 'cleverness', even though she questions her own interests in science.

Thus, Samantha's identification with science can be seen as the performativity of intelligence (Butler, 1999). For Samantha, it is not the actual science (and 'scientific identity') that she is keen to associate with, but the characteristics within her understandings of a 'scientific identity', which includes that of a 'clever' identity. As can be seen, the study of science does not necessary imply the take up of a 'scientific identity' per se, as the study of triple science is constructed (by Samantha and her peers at least) as a marker for 'cleverness' and 'high achieving'. Samantha's case can also shed light on expectations surrounding British-Indian girls as 'high achievers', where (perceived) prestigious subjects such as science may be regarded as a site where competence can be demonstrated and performed. In this case, Samantha's family cultural discourses of 'high achievement' as something that is appropriate and desirable for British-Indian girls may have created an alternative space for identity negotiation within the seemingly male-dominated science environment, such as through performances of 'cleverness'. Thus, it is argued that for Samantha, the combination of her habitus, capitals and performativity of intelligence contributes to the maintenance of motivation to study triple science, despite a decline in her interest in science over the primary to secondary school transfer.

\section{The Case of Fay: ('Short-term') Achievement without Engagement}

Fay is a 13-year-old working class girl from a Bangladeshi ethnic background and is also regarded as a high achieving pupil, being in the 'top set' for Year 9 science. Unlike Samantha, who felt disillusioned by secondary school science (Murphy \& Beggs, 2005), Fay claimed science to be one of her favourite subjects, and voiced interest in biology ('biology is the best cos I'm really good at it') and chemistry, with physics her only dislike (Hughes, 2001; Murphy \& Whitelegg, 2006). Her like of particular science classes, however, appears to correspond to certain teachers who 'let her off chatting', since she claimed to have disliked science in the previous school year, explaining that the teacher then was impatient and unhelpful ('last year our teacher who probably explains it once but if you didn't get it, it's your own problem ... he wasn't very great'). While Fay is undecided about her choice of GCSE science ('I don't know about singles or doubles [science]'), she made clear of her intentions to avoid physics ('I don't like physics ... I'm rubbish at it'). Like Samantha, Fay perceived scientists as 'intelligent people' 
and she articulated an egalitarian discourse of science, claiming that 'science is for anyone who has got the brains for science'. In a similar vein to Samantha, Fay constructed science as an achievable domain open for anyone who is 'clever' enough to succeed. However, Fay also distanced girls' involvement in science by suggesting 'girls are more into how they look ... care about make-up and stuff, which seem to align with her own interest of hetero-feminine performativity (Kelly, 1985; Walkerdine, 1989). Fay also made an implicit association between male dominance in science and 'cleverness' by implying 'most science teachers are men as well' while claiming 'intelligent people' as 'people who are good at science'. In this case, Fay appears to construct science as a field for clever men, while 'normal' girls, like her, are more interested in hetero-feminine investments (Francis, 2000a, 200ob; Whitehead, 1996). Indeed, international studies have suggested that the 'objective', and/or 'masculine' nature of science and science-related careers to be unattractive and undesirable for girls (e.g. Christidou, 2006 in Greece; Jones, Howe, \& Rua, 2000 in US; Lui, Hu, Jiannong, \& Adey, 2010 in China; Masnick, Valenti, Cox, and Osman, 2010 in UK). According to Masnick et al. (2010), the lack of females in the field of (physical) science reflects the tendency of women to be interested in 'socially valued', or 'people-oriented' careers (Miller, Blessing, \& Schwartz, 2006). Thus, Fay's disinterest in science may reflect her 'masculine' constructions of science as well as her aspirations to be 'famous'.

As such, while Samantha and Fay are both 'high achievers' in science, Fay does not share Samantha's goal of performing 'cleverness' through the study of (triple) science. Instead, Fay is interested in popular celebrity culture which she aspires to embrace through a future career in 'show business'. In this section, the case of Fay is analysed to show how capitals seemingly related to science may not translate into scientific (and even academic) interests (and achievements). The potential limits of a Bourdieuian analytic lens is implicated here, since Bourdieu viewed capitals as 'convertible' resources (Bourdieu, 1986), and it is suggested for Fay, gender performativity may have resulted in her science-related resources to be 'under-utilised' and resisted.

On the surface, Fay appears to posses a similar habitus to Samantha, with parental resources facilitating high achievement. However, the tensions between available capitals and hetero-feminine performances can also complicate Fay's academic attainments and aspirations. Like Samantha, Fay's parents are 'active participants' in her education and her parents are particularly enthusiastic towards science and maths. Unlike the British-Bangladeshi parents reported in Smart and Rahman (2009, p. 45) who 'did not indicate any particular subject preferences', Fay noted her mum's emphasis for her 'to be good at maths' because of its perceived necessity in life and job (Mendick, 2005), although Fay refuted this by responding 'you need English because, obviously, we're in England'. She said her mum also tried to 'force' her to join the school science club, as well as 'monitoring' her homework ('My mum forces me to do homework! If I don't do it she will watch me do it ... she would sit behind me and make sure I'm not chatting [on the Internet]') while her dad 'tried to make' her watch the Discovery Channel. In this sense, (science-related) cultural capitals are available to Fay but subsequently rejected by her, which, it will now be argued, is related to her stated interest in 'showbiz'.

According to Fay, her interest in the entertainment industry stems from her desire to be 'famous' ('since I was very little I always wanted to be famous ... I still want to be famous, very 
famous'). She dreamt of achieving this by becoming an 'actor, model or singer or whatever'. Fay's career aspirations may be shared by many young 'working class' girls who are attracted by the glamour of celebrity lifestyle and fame (e.g. Walkerdine, 1997). Fay was heavily interested and invested in the field of glamour, beauty and the performances of hetero-femininity ('there is something going on about doing makeup and things on other people [in school], and I want to do that, with my friend'), as exemplified by each of the study's four one-hour science classroom observations, which noted Fay to be checking her appearance on a regular basis. For example, in one of the observations the following was noted:

Fay continues to check her make-up as Mr Tallman walks away from the table, and began applying lip gloss. Fay passes her lip gloss to her friend, who held but did not use it. Fay continues checking her make-up holding a small mirror, and applies a few brushes to her face, as well as talking to the other girls at the table. Fay frequently checks her make-up. Fay then applies mascara suspiciously, most probably after her nail varnish was confiscated by Mr Tallman (Observation note, November $5^{\text {th }}$ 2009).

As can be seen, Fay appears to invest considerable time in her hetero-feminine appearance, and such practices were also supported by the girls at her classroom table. While previous classroom observation studies on gender and science tend to focus on teacher-student interactions, such that boys generally receives more attention from teachers than girls (e.g. Greenfield, 1997; Taber, 1992), the focus on particular students, in this case Fay, appear to have shed light on the performances of femininity within the (science) classroom (Francis, 200oa). Thus, while Fay does not seem to possess social capital in relation to science, her investment and maintenance of hetero-femininity are supported within her peer group, reinforcing her performative identity (and doings) of 'girling' (Butler, 1993). In the science class, Fay was noted as never participating in question and answer sessions, as well as being quiet and anonymous in classroom discussions, which, as mentioned earlier, constitutes the dominant discourse of Britain Asian (Indian, Pakistani, Bangladeshi) schoolgirls (Shain, 2003). According to Fay, her withdrawal from science classroom discussions was ‘because we either we don't get it or we didn't listen, but even when I do listen, I like, I don't understand it, it's hard'. However, Fay also describes herself as 'chatty' and 'hyper' and classroom observations also noted Fay to frequently and quietly talk amongst her friends at her table, with conversations including 'is my hair alright?', 'that's a nice jacket', 'I've watched it ... He's so cute' and 'I'm not going out with him!. Thus, Fay's engagement with science in the classroom is questionable, but her performances of 'girling' (Butler, 1993) are more apparent, since her investment in hetero-feminine make-up and small group chat dominated classroom observation notes.

It is argued that Fay's top set status in science reflects her desire (or practice) of achieving in school, rather than any particular interest in science (i.e. she is motivated to do well in science as part of doing well in school). Such an approach to education appears to be promoted within her family, as mentioned earlier, resulting in a habitus that is 'educationally oriented' (e.g. Francis \& Archer, 2005). Unlike 'Ruby' - an African American schoolgirl in Brickhouse and Potter's (2001) case study analysis - who was able to balance her computing identity with a mainstream femininity (e.g. interest in modelling and cheerleading), Fay's 
construction of a desirable female identity seems to surround her ambitions to be in the entertainment business and the performances of hetero-femininity. While Ruby's dad was involved in computing, and that technology was a central topic of communication at her home, Fay was also equipped with resources and exposures to science, through her parental (cultural) capitals. However, Fay's disinterest in science, despite being in the top set for science, is perhaps a result of her desire to be in the spotlight of glamour and fame. From classroom observations, Fay's heavy investment (and performance) in her appearance (and hetero-femininity) is interesting because existing literatures (e.g. Archer et al., 2007) found that the construction of hetero-femininities amongst 'working class' girls can also lead to their disengagement from education and schooling. Indeed, Fay's apparent underperformance in her recent science tests may be an indicator of such trajectory, as her level five grades are well below the expectations from both her science teacher and herself of at least level six.

Fay's fluidity of gender performance is also worth noting. On the one hand, Fay's working class background and her investment in hetero-femininity positions her as 'in danger' of educational disengagement (Archer et al., 2007). In fact, while Fay's science teacher, $\mathrm{Mr}$ Tallman, regarded her as competent enough to study science at the highest level for GCSE (i.e. triple science); he felt the likelihood of Fay opting for triple science was extremely low, because he saw little or no interest from her in science. As Mr Tallman commented on Fay:

It's a little early days to say which ways she swings at the moment ... I would like to get her more interested ... [but] I honestly think with someone like her, I would probably fail in trying to get her interested ... but she's doing ok because that's what she got to do, not necessary because inspired to do it.

Indeed, Fay was also uncertain about her GCSE choice in science. On the other hand, like Samantha, Fay's educationally oriented habitus, supported in her family, ensures that Fay values and performs academically. Indeed, classroom observations, as mentioned earlier, noted Fay to be quiet and anonymous in science lessons, and studies in the US have found 'high' achieving African American schoolgirls who adopted the strategy of staying quiet in the science classroom to be negatively perceived by their teachers as incompetent or disinterested (e.g. 'Crystal' in Brickhouse and Potter, 2001; 'Stella' for maths in Lim, 2008). However, Fay is British Asian and her teacher perceived her as capable, which may also shed light on the influences of the dominant Britain Asian schoolgirl discourse as quiet but also hardworking and 'high' achieving (Shain, 2003). In this case, Fay's educationally oriented habitus may serve as the foundation in her constructions and aspirations of hetero-feminine appearances and careers, meaning her goal to be 'famous' in the show business resides within (and after) particular academic educations.

Fay's 'high achieving' status, however, may also be under threat, as hinted at by her declining grades in science. Thus, it remains to be seen whether an educationally oriented habitus can provide Fay with the resistance to 'working class' girl trajectories of school disengagement (Archer et al., 2007). The case of Fay (and Samantha) can also shed light on Francis et al's (2010) study on 'high-achieving and popular' pupils, since only 2 of the 22 pupils inhabiting such status are from minority ethnic backgrounds (one Afro-Caribbean boy and one 
Chinese girl). Fay's declining achievement and her pursuit of popularity, demonstrated through her heavy hetero-feminine investments as well her aspirations in popular culture, may suggest that the maintenance of a 'high-achieving and popular' identity are complicated by ethnicity.

\section{Discussion}

This paper draws insights into the ways in which minority ethnic students construct and identify with the field of science through Bourdieu's (1986) conceptual tools and the lens of identity as performativity (Butler, 1999). In the case of Samantha and Fay, discourses surrounding the family, gender and cultural expectations appear to operate in complex ways.

Samantha's desire to identify with triple science stems from her construction of the subject as being 'smart' and 'clever' (Osborne et al., 2003), which is consistent with her educationally oriented habitus and is supported by available social and cultural capitals. While Samantha (and her close group of friends) were labelled as 'nerds' and 'geeks' by other pupils, such remarks were 're-interpreted' in a positive light, as compliments and recognitions for competent students. Such reconstructions were made possible through Samantha's peer group, who all commanded an educationally oriented habitus, as well as the desire for a 'clever' identity. Similarly, Varma (2007) examined the role of 'geek culture' as potentially dissuading women from the field of computer science, but concluded that minority ethnic women are 'less likely to resent being associated with geek culture' because of the perceived 'social prestige' and 'good paying job' associated with computer science which 'outweigh the stigma' (Varman, 2007, p. 373). Samantha's cultural and social capital was also significant, with various resources available from her parents, older brother and her uncle and aunty (Bourdieu, 1986). Fay, on the other hand, does not view science in the same way. While possessing an educationally oriented habitus, which ensures a pro-school approach to education, Fay shows little or no interest in (triple) science. Fay's desire to enter show business and become famous is seen through her heavy investment in hetero-femininity and 'girling' (Walkerdine, 1997). While Fay appears to possess similar capitals (in science) as Samantha, it is not the same, with the notable difference in the availability of social capitals. Fay does not have a brother who is about to complete triple science and she also lacks the (science-related) social capital of Samantha in the sense of peer support and extended familial network. Fay's social network comprises of girls who also tend to invest considerably in classroom hetero-femininity meaning that 'nerd' (or 'geek') identity typically associated with science is not desirable for her.

While Fay's investment in hetero-femininity is apparent within the classroom, Samantha's lack of hetero-feminine investment (in school) may also be deliberate (Renold, 2001). Ong (2005) noted female physics undergraduates from ethnic minority backgrounds who purposefully limited their hetero-femininity by wearing trousers and no make-up in order to appear as creditable and competent scientist-to-be. Likewise, a 'clever' identity may be undermined if engaged with hetero-feminine activities, as implied in Samantha's construction and dismissal of popular girls as immature and only talking about boys. While recent studies have discussed the maintenance of popularity amongst high achieving pupils (e.g. Francis et al., 2010), the 'incompatibility' between these (apparently) polar opposites may still inhabit within Samantha's construction of the 'clever' identity, which entails characteristics of the 'good pupil' 
who works hard, behaves well and achieves academically.

While performances of femininity can be dis/encouraged by peer groups, it can also be shaped by discourses within the school (and the family); even though there are no indications to suggest the school Samantha attended was any different from Fay's with regards to the discipline or performances of femininity. Indeed, even though Fay was frequently noted to apply make-up in the science classroom, she did it furtively as her teacher would and had confiscated (and disposed of) her cosmetic accessories.

It is important to note that the 'educationally oriented' habitus inherited by both Samantha and Fay are somewhat 'different' - in particular, it is argued that Samantha's educationally orientated habitus appears to be 'long-term', while Fay's educationally oriented habitus is comparable to 'short-term', and this can be seen through the example of parental involvement in homework. While Fay's mum actively 'monitors' her doing homework, as Fay is easily distracted, Samantha's mum knows she will do her homework, because Samantha selfregulates (Foucault, 1985) her completion of homework. As can be seen, Samantha seems to have internalised a particular approach to education which may depict her educationally oriented habitus as 'long-term', as it seems normal for Samantha to 'value' education, such as her self-regulation of homework. Indeed, Samantha's insistence to study triple science despite her declining interest is also applicable, because on the one hand, it can be read as an example of her desirability to perform intelligence (Butler, 1999), and on the other hand, it also demonstrates Samantha's educationally oriented habitus to value the subject of science as beneficial for her educational (or occupational) future (Brickhouse \& Potter, 2001). While Brickhouse et al. (2000) raised concern over the long term engagement of girls who only aspired to study and perform in school science as part of being a 'good' student, Samantha has aspirations to be a doctor and her recognition of the value of triple science for her career may provide her with ammunition to resist or disrupt the 'leaky pipeline' of girls' gradual disengagement from science (Blickenstaff, 2005). Fay's educationally oriented habitus, however, may be 'short-term', as her 'high' achievement may be argued as actively maintained by her mum through continuous (and 'active') participation in her education (e.g. 'forcing' her to do homework), meaning Fay's 'top set' status and success in education may be a smokescreen that could evaporate if 'active' parental involvement is withdrawn, or when parental participation reaches a point of saturation in terms of academic returns (e.g. Fay's grades are declining). In this case, the trajectory of disengagement of 'working class' girls from education, which may be signalled through continuous hetero-feminine investments (Archer et al., 2007), or the lack of 'educational' self-regulation, such as the completion of homework, remains a possibility for Fay.

The ways in which minority ethnic students - in this case, two 13-year-old 'high achieving working class' British Asian girls - associate with the field of science can encompass a range of social, cultural and structural factors. Previous studies in gender, ethnicity and science conclude with a call for school science to be more 'girl friendly' (e.g. Jones et al., 200o) and to create a more 'hospitable environment' for minorities (Ong, 2005) in order to (re)engage girls and minority ethnic groups with science (Häussler \& Hoffmann, 2002). While Fay and Samantha are both 'high' achievers, their trajectories appear consistent with the 'science leaky pipeline' in the UK where British-Bangladeshi students (e.g. Fay) are underrepresented and British-Indian students (e.g. Samantha) are overrepresented in the field of science study (Elias 
et al., 2006), which may also suggest the gender underrepresentation of girls in science (Murphy \& Whitelegg, 2006) are complicated by ethnicity. This paper on Fay and Samantha demonstrates how different forms of identity performativity (e.g. being 'clever' versus being 'famous') and educationally oriented habitus (e.g. 'long-term', 'short-term') can complicate girls constructions and associations with science and aspirations. While this study presents only a 'snapshot' of the views and experiences of two British-Asian schoolgirls in their identifications with science, the use of Bourdieuian theory hopes to have presented new insights into the complex processes and negotiations, between identities and cultural discourses, through students' identification with science.

\section{Acknowledgements}

The author would like to express deep gratitude to Louise Archer and Justin Dillon for their continuous support, advice and supervision. The author would like to thank the participants in this study for their contributions. This study is part of a doctoral research funded by the ESRC (ES/Hoo5072/1) and the Rosalind Driver Scholarship Fund at King's College London. It is a studentship as part of the ASPIRES project at King's, a five-year longitudinal study entitled 'Science Aspirations and Career Choice: Age 10-14' funded by the ESRC (RES-179-25-00o8). The ASPIRES project is part of the ESRC Targeted Initiative on Science and Mathematics Education (TISME).

\section{References}

Adamuti-Trache, M., \& Andres, L. (2008). Embarking on and Persisting in Scientific Fields of Study: Cultural capital, gender, and curriculum along the science pipeline. International Journal of Science Education, 30(12), 1557-1584.

Aikenhead, G. S. 1996. Science education: Border crossing into the subculture of science. Science Education, 27, 1-52.

Archer, L. \& Francis, B. (2007). Understanding Minority Ethnic Achievement: the role of race, class, gender and 'success'. London, Routledge.

Archer, L., Halsall, A., \& Hollingworth, S. (2007). Class, gender, (hetero)sexuality and schooling: paradoxes within working class girls' engagement with education and post-16 aspirations. British Journal of Sociology of Education, 28(2), 165-180.

Asher, N. (2002). Class Act: Indian American High School Students Negotiate Professional and Ethnic Identities. Urban Education, 37(2), 267-295.

Baker, D. (1998). Equity issues in science education. In B. J. Fraser, and K. G. Tobin (Ed.), International handbook of science education (pp. 869-896). Boston, Kluwer.

Blickenstaff, J. C. (2005). Women and science careers: leaky pipeline or gender filter? Gender and Education, 17(4), 369-386.

Bourdieu, P. (1977). Outline of a Theory of Practice. Cambridge, Cambridge University Press.

Bourdieu, P. (1986). The forms of capital. In J. Richardson (Ed.) Handbook of Theory and Research for the Sociology of Education (pp. 241-258). New York, Greenwood.

Brandt, C.B., Shumar, W., Hammond, L., Carlone, H., Kimmel, S., \& Tschida, C. (2010). 
Habitus, social fields, and circuits in rural science education. Cultural Studies of Science Education, 5(2), 477-493.

Brickhouse, N. W. \& Potter, J. T. (2001). 'Young women's scientific identity formation in an urban context' in Journal of Research in Science Teaching, 38(8), 965-980.

Brickhouse, N. W., Lowery, P., \& Schultz, K. (2000). What kind of a girl does science? The construction of school science identities. Journal of Research in Science Teaching, 37(5), 441458.

Brotman, J. S., \& Moore, F. M. (2008). Girls and science: A review of four themes in the science education literature. Journal of Research in Science Teaching, 45(9), 971-1002.

Burman, E., \& Parker, I. (1993). Discourse analytic research: repertories and readings of text in action. London, Routledge.

Burnell, D. J. B. (2009). Challenges for the future. The Journal of the Foundation for Science and Technology, 19(10), 19-20.

Burr, V. (2003). Social Constructionism. $2^{\text {nd }}$ Edition. East Sussex, Routledge.

Butler, J. (1993). Bodies That Matter. London, Routledge.

Butler, J. (1999). Gender Trouble: Feminism and the Subversion of Identity. $10^{\text {th }}$ Anniversary Edition. London, Routledge.

Ceci, S. J., \& Williams, W. M. (2007). Why aren't more Women in Science? Top Researchers Debate the Evidence. Washington, DC, American Psychological Association.

Christidou, V. (2006). Greek Students' Science-related Interests and Experiences: Gender differences and correlations. International Journal of Science Education, 28(10), 1181-1199.

Cohen, L., Manion, L., \& Morrison, K. (2000). Research Methods in Education. $5^{\text {th }}$ Edition. London, RoutlegdeFalmer.

Department of Children, Schools and Families (DCSF) (2002). Secondary School Performance Tables 2002: How to Read the Tables. Retrieved September 30, 2010 from http://www.education.gov.uk/performancetables/schools_02/ secza.shtml

Department of Children, Schools and Families (DCSF) (2009). Statistical First Release: GCSE and Equivalent Examination Results in England, 2007/o8 (Revised). London: DCSF. SFR $02 / 2009$.

Demie, F., \& Lewis, K. (2010). White working class achievement: an ethnographic study of barriers to learning in schools, Educational Studies, First published on: 16 September 2010 (iFirst).

DeWalt, K. M \& DeWalt, B. R. (2001). Participant Observation: A Guide for Fieldworkers. Walnut Creek, CA, Altamira Press.

Elias, P., Jones, P., \& McWhinnie, S. (2006). Representation of Ethnic Groups in Chemistry and Physics: a report prepared for the Royal Society of Chemistry and the Institute of Physics. London, Royal Society of Chemistry/Institute of Physics.

Elmesky, R., \& Tobin, K. (2005). Expanding our understandings of urban science education by expanding the roles of students as researchers. Journal of Research in Science Teaching, ${ }_{22}(7)$, 807-828.

Foucault, M. (1980). Power/Knowledge: Selected Interviews and Other Writings, 1972-1977. (C. Gordon, Ed.). London, Harvester Wheatsheaf.

Foucault, M. (1985). The use of pleasure: the history of sexuality, Vol. 2. New York: Vintage. 
Francis, B. (2000a). Boys, girls, and achievement: addressing the classroom issues. London, Routledge.

Francis, B. (200ob). The gendered subject: students' subject preferences and discussions of gender and subject ability. Oxford Review of Education, 26(1), 35-48.

Francis, B., \& Archer, L. (2005). British-Chinese pupils' constructions of gender and learning. Oxford Review of Education, 31(4), 497-515.

Francis, B., Skelton, C., \& Read, B. (2010). The simultaneous production of educational achievement and popularity: how do some pupils accomplish it? British Educational Research Journall, 36(2), 317-340.

Gilleece, L., Cosgrove, J., \& Sofroniou, N. (2010). Equity in mathematics and science outcomes: Characteristics associated with high and low achievement on PISA 2006 in Ireland. International Journal of Science and Mathematics Education, 8(3), 475-496.

Greenfield, T. A. (1997). Gender- and grade-level differences in science interest and participation. Science Education, 81(3), 259-276.

Guillemin, M., \& Gullam, L. (2004). Ethics, Reflexivity, and "Ethically Important Moments" in Research. Qualitative Inquiry, 10(2), 261-280.

Hall, S. (1990). Cultural Identity and Diaspora. In J. Rutherford (Ed.) Identity: Community, Culture, Difference (pp. 222-237). London, Lawrence \& Wishart.

Häussler, P., \& Hoffmann, L. (2002). An intervention study to enhance girls' interest, selfconcept and achievement in physics classes. Journal of Research in Science Teaching, 30(9), 870-888.

Harker, R. K. (1984). On Reproduction, Habitus and Education. British Journal of Sociology of Education, 5(2), 117-127.

Hughes, G. (2001). Exploring the Availability of Student Scientist Identities within Curriculum Discourse: an anti-essentialist approach to gender-inclusive science. Gender and Education, 13(3), 275-290.

Jenkins, E. W., \& Nelson, N. W. (2005). Important but not for me: students' attitudes towards secondary school science in England. Research in Science \& Technological Education, 23(1), 41-57.

Jones, P., \& Elias, P. (2005). Science, Engineering and Technology and the UK's Ethnic Minority Population: A Report for the Royal Society. Warwick Institute for Employment Research, University of Warwick.

Jones, M. G., Howe, A., \& Rua, M. J. (2000). Gender Differences in Students' Experiences, Interests, and Attitudes toward Science and Scientists. Science Education, 84(2), 180-192.

Kelly, A. (1985). The Construction of Masculine Science. British Journal of Sociology of Education, 6(2), 133-154.

Lewis, J. L., Menzies, H., Nájera, E. I \& Page, R. N. (2009). Rethinking trends in minority participation in the sciences. Science Education, 93(6), 961-977.

Lim, J. H. (2008). The road not taken: two African-American girls' experiences with school mathematics. Race Ethnicity and Education, 11(3), 303-317.

Liu, M., Hu, W., Jiannong, S., \& Adey, P. (2010). Gender Stereotyping and Affective Attitudes Towards Science in Chinese Secondary School Students. International Journal of Science Education, 32(3), 379-395. 
Masnick, A. M., Valenti, S. S., Cox, B. D., \& Osman, C. J. (2010). A Multidimensional Scaling Analysis of Students' Attitudes about Science Careers'. International Journal of Science Education, 32(5), 653-667.

Mendick, H. (2005). Why Do More Boys than Girls Choose to Study Mathematics at AS-Level in England?. British Journal of Sociology of Education, 26(2), 235-251.

Miles, M. B. \& Huberman, A. M. (1994). Qualitative data analysis. $2^{\text {nd }}$ Edition. Thousand Oaks, CA, SAGE.

Miller, P. H., Blessing, J.S., \& Schwartz, S. (2006). Gender Differences in High-school Students' Views about Science. International Journal of Science Education,28(4),363-381.

Morrow, V. (1999). Conceptualising Social Capital in Relation to the Well-Being of Children and Young People: A Critical Review. Sociological Review, 47(4), 744-766.

Murphy, C., \& Beggs, J. (2005). Primary science in the UK: a scoping study. Final report to the Wellcome Trust. London, Wellcome Trust.

Murphy, P., \& Whitelegg, E. (2006). Girls in the Physics Classroom: A Review of Research on the Participation of Girls in Physics. London, Institute of Physics.

National Academy Press (2010). Expanding Underrepresented Minority Participation: America's Science and Technology Talent at the Crossroads. Retrieved on October 6, 2010 from http://www.nap.edu/catalog/12984.html

Nayak, A., \& Kehily, M. J. (2006). Gender undone: subversion, regulation and embodiment in the work of Judith Butler. British Journal of Sociology of Education, 27(4), 459-472.

Ong, M. (2005). Body Projects of Young Women of Color in Physics: Intersections of Gender, Race, and Science. Social Problems, 52(4), 593-617.

Osborne, J. (2008). Engaging young people with science: does science education need a new vision? School Science Review, 89(328), 67-74.

Osborne, J. \& Dillon, J. (2008). Science Education in Europe: Critical Reflections. London, Nuffield Foundation.

Osborne, J., Simon, S., \& Collins, S. (2003). Attitudes towards science: a review of the literature and its implications. International Journal of Science Education, 25(9), 1049-1079.

Rapley, T. J. (2001). The art(fulness) of open-ended interviewing: some considerations on analysing interviews. Qualitative Research, 1(3), 303-323.

Renold, E. (2001). 'Square-girls', Femininity and the Negotiation of Academic Success in the Primary School. British Educational Research Journal, 27(5), 577-588.

Renold, E. \& Allan, A. (2006). Bright and Beautiful: High achieving girls, ambivalent femininities, and the feminization of success in the primary school. Discourse: Studies in the Cultural Politics of Education, 27(4), 457-473.

Rhodes, P. J. (1994). Race-of-interviewer effects: a brief comment. Sociology, 28(2), 547-558.

Ryan, A. M. (2001). The Peer Group as a Context for the Development of Young Adolescent Motivation and Achievement. Child Development, 72(4), 1135-1150.

Shain, F. (2003). The schooling and identity of Asian girls. Staffordshire, Trentham Books.

Smart, S. \& Rahman, J. (2009). Bangladeshi girls choosing science, technology, engineering and maths: An exploration of factors that affect Bangladeshi girls' achievement in, engagement with, and aspirations in STEM subject areas. Research Paper by London East Thames Gateway Aimhigher and CfBT Education Trust. 
Snape, D., \& Spencer, L. (2003). The Foundations of Qualitative Research. In J. Ritchie and J. Lewis (Ed.), Qualitative Research Practice: A Guide for Social Science Students and Researchers (pp. 1-23).London, SAGE.

Taber, K. S. (1991). Gender Differences in Science Preferences on Starting Secondary School. Research in Science \& Technological Education, 9(2), 245-251.

Tai, R. H., Qi Liu, C., Maltese, A. V., \& Fan, X. (2006). Planning Early for Careers in Science. Science, 312, 1143-1145.

Thomson, S. (2008). Examining the evidence from TIMSS: Gender differences in Year 8 science achievement in Australia. Studies in Educational Evaluation, 34 (2), 73-81.

Varma, R. (2007). Women in Computing: The Role of Geek Culture. Science as Culture, 16(4), 359-376.

Walkerdine, V. (1989). Femininity as performance. Oxford Review of Education, 15(3), 267-279.

Walkerdine, V. (1997). Daddy's girl: young girls and popular culture. Cambridge, Massachusetts, Harvard University Press.

Whitehead, J. M. (1996). Sex stereotypes, gender identity and subject choice at A-level. Educational Research, 38(2), 147-160.

Zhou, M. (2005). Ethnicity as social capital: community-based institutions and embedded networks of social relations. In G. C. Loury, T. Modood and S. M. Teles (Ed.) Ethnicity, social mobility and public policy: comparing the USA and UK (pp. 131-159). Cambridge, Cambridge University Press.

\footnotetext{
${ }^{\mathrm{i}}$ General Certificate of Secondary Education (GCSE) is an academic qualification generally taken by students aged 14-16 (in England. Wales and Northern Ireland). In academic or governmental publications, GCSE are sometimes referred as Key Stage 4.

${ }^{\text {ii }}$ Doctoral study began in January 2009 and is due to be completed by December 2011. This paper reports on the early findings of the overall study.

iii Of the 7 schools participated, 4 are co-educational state schools (contributing 35 participants) and 3 Chinese complimentary schools (contributing 11 of 13 Chinese participants). Chinese complimentary schools were approached due to the lack of Chinese participants in the 4 state schools (only 2 ).

${ }^{\text {iv }}$ The schools were 'typical' in their respective local authorities, such as GCSE achievements.

${ }^{v}$ Students were also asked in the interviews to self-define their ethnic backgrounds.

${ }^{v i}$ Some interview locations were noisier, such as at the corner of a large hall, due to space limitations, which was frequent in Chinese complimentary schools.

vii Ofsted is a government department responsible for inspecting the standards of (state or private) schools in England.

viii GCSE science typically consists of three different levels: 'single award', 'double award' and 'triple award', which corresponds to the number of GCSE it is worth. Triple award science, or triple science, is worth 3 GCSEs and is the most comprehensive course of science available at GCSE. For more information, http://www.bbc.co.uk/schools/gcsebitesize/science/

${ }^{\mathrm{ix}}$ In the doctoral study, discussion groups were conducted with students from Afro-Caribbean, Pakistani, Indian and Chinese ethnic backgrounds. The purpose of discussion groups was to shed light on the experiences of minority ethnic pupils in science through student interactions and discussion.

' 'Safe routes' in this context can be understood as pathways that one considers as 'safe' and possible, because prior experience or knowledge of people who has succeeded in such path.
} 